\title{
Investigação sobre as relações familiares de idosos com ideação suicida e tentativa de suicídio
}

Research on family relations of elderly people with suicidal ideation and suicide attempt

Patrícia Rafaele Dos Reis Albuquerque ${ }^{1}$, Ana Célia Sousa Cavalcante ${ }^{2}$, Liliane Leite Moreira ${ }^{3}$, Maria Helena Chaib Stegun ${ }^{4}$, Ismael Mendes Da Silva ${ }^{5}$, Cláudia Aline De Brito Oliveira $^{6}$, Patrícia Carvalho Moreira ${ }^{7}$, Brunna Verna Castro Gondinho ${ }^{8}$.

\section{Resumo}

Os fatores de risco para o suicídio em pessoas idosas são, principalmente, relacionados a morte de entes queridos, doenças e relações familiares. Assim, este artigo analisa as relações familiares de idosos com ideação e tentativas suicidas. Realizado na cidade de Teresina-PI, visto que se encontra entre os dez municípios nacionais com maior índice de ocorrência de suicídio entre idosos. Verificou-se que os idosos pesquisados vivenciam conflitos nas relações familiares, sentem-se desprezados, abandonados e rejeitados pelos familiares, motivos pelos quais se culpam; convivem em meio familiar, mas de modo isolado, vivem isolados socialmente e em

\footnotetext{
${ }^{1}$ Psicóloga. Especialista em Saúde Mental e Atenção Psicossocial - FSF/CENSUPEG.

${ }^{2}$ Mestra em Saúde Coletiva - UNIFOR. Professora do Curso de Psicologia da FACID/DEVRY, Teresina-PI.

${ }^{3}$ Mestra em Ciências e Saúde - UFPI. Prof ${ }^{\mathrm{a}}$ do Curso de Psicologia da FACID/DEVRY, Teresina-PI.

${ }^{4}$ Especialista em Saúde Pública - Universidade de Ribeirão Preto. Prof ${ }^{a}$ do Curso de Psicologia da FACID/DEVRY.

${ }^{5}$ Graduado em Psicologia pela Faculdade Santo Agostinho. Especialista em Saúde Mental e Atenção Psicossocial pela Faculdade São Fídelis.
}

Rev. Gestão \& Saúde (Brasília) Edição Especial, fev. 2019. sofrimento psíquico, com transtornos mentais, que favorecem a ideação suicida. Assim, os idosos pesquisados buscam a religiosidade como formas de enfrentamento e de dar sentido à vida.

Palavras-chave: Ideação Suicida. Idoso.

Relações Familiares. Tentativa de Suicídio.
Abstract
Risk factors for suicide in the elderly are mainly related to death of loved ones, illness and family relationships. Thus, this article analyzes the family relationships of the elderly with ideation and suicidal attempts. Made in the city of Teresina-PI, since it is among the ten municipalities with the highest rate of suicide among the elderly. It was verified that the surveyed

\footnotetext{
${ }^{6}$ Graduado em Psicologia pela Faculdade Santo Agostinho. Especialista em Saúde Mental e Atenção Psicossocial pela Faculdade São Fídelis.

${ }^{7}$ Graduada em Psicologia (UESPI), Especialista em Tanatologia (FATENE), Mestre em Antropologia (UFPI). Membro Pesquisador do Laboratório de Tanatologia e Psiquiatria em outras condições Médicas (UFRJ) e Professora do Centro de Ciências da Saúde (UESPI).

${ }^{8}$ Graduada em Odontologia (UFPI), Mestre em Odontologia em Saúde Coletiva (FOP/UNICAMP) e Doutoranda em Odontologia - Área: Saúde Coletiva (FOP/UNICAMP).
} 
Revista Eletrônica Gestão \& Saúde ISSN: 1982-4785 Albquerque PRR, Cavalcante ACS, Oliveira CAB et al

elderly experience conflicts in family relationships, feel scorned, abandoned and rejected by relatives, reasons for which they blame themselves; they live together in a family environment, but in an isolated way, they live socially isolated and in psychic suffering, with mental disorders, which favor suicidal ideation. Thus, the researched elderly seek religiosity as ways of coping and giving meaning to life.

Keywords: Suicidal Ideation. Old man. Family relationships. Suicide attempt.

\section{Introdução e Revisão da}

\section{Literatura}

Segundo a Organização Mundial de Saúde ${ }^{(1)}$ os altos índices de suicídio afligem países desenvolvidos e em desenvolvimento, os resultados encontrados por pesquisadores europeus avaliam que o número de tentativas de suicídio pode ser até 40 vezes maior que o de suicídio fatal. Dessa forma, a morte por suicídio é um sério problema de saúde pública, já que aproximadamente um milhão de pessoas morreram por suicídio, sendo a taxa global de 16 por 100 mil habitantes ${ }^{(1)}$.

Suicídio, também chamado tecnicamente "comportamento suicida fatal", é o resultado de um ato deliberadamente empreendido e executado com pleno conhecimento ou previsão de seu desenlace, ou seja, na sua definição, a intencionalidade de dar cabo à vida por quem comete o suicídio é o elemento
Investigação sobre as relações familiares...

chave $^{(2)}$, já a ideação suicida se refere aos vários graus de intensidade do pensamento de se matar. Alguns psicanalistas acrescentam uma nova categoria: o suicídio inconsciente, para designar casos de indivíduos que se colocam em situações de risco fatal, enfrentando certos estilos de vida autodestrutivos ou mesmo provocando doenças em si mesmo. A tentativa de suicídio ou comportamento suicida não fatal, por sua vez, nomeia os atos cometidos por indivíduos que pretendem se matar, mas cujo desfecho não resulta em óbito ${ }^{(3)}$.

A ideação e tentativas suicidas sempre estão associadas e, em geral, precedem ao ato fatal de ordem qualitativa, na interlocução, foram os próprios idosos os narradores das situações que os levam ou levaram a preferir a morte a viver em intenso sofrimento. A partir das histórias narradas pelos familiares brasileiros sobre as mortes de seus idosos, pode-se inferir que os problemas que os levam a morte auto infligida, quase sempre, são: transtornos mentais, conflitos nas relações familiares, dificuldades da aceitação do envelhecimento que com o cotidiano tornam suas vidas, em algum momento, insuportável $^{(4)}$.

Neste sentido, segundo as autoras supracitadas, tem-se que, os fatores de risco para o suicídio em pessoas idosas são, principalmente, morte de uma pessoa querida, mormente, de um cônjuge, doença terminal com dores incontroláveis, medo do 
Revista Eletrônica Gestão \& Saúde ISSN: 1982-4785 Albquerque PRR, Cavalcante ACS, Oliveira CAB et al

prolongamento da vida sem dignidade, trazendo prejuízos econômicos e emocionais aos familiares, isolamento social, mudanças nos papeis sociais que lhes conferiam reconhecimento, ou situações de dependência física ou mental frente às quais o idoso se sente humilhado.

O presente estudo teve sua origem em uma pesquisa de âmbito nacional, intitulada "Estudo sobre tentativas de suicídio em idosos sob a perspectiva da saúde pública", realizada pela Fundação Oswaldo Cruz, Ministério da Saúde, Escola Nacional de Saúde Pública - ENSP e Centro Latino Americano de Estudos de Violência e Saúde / FIOCRUZ, com apoio do CNPq.

Nesse contexto, o problema da pesquisa foi verificar as implicações que as relações familiares podem ter na ideação e tentativas de suicídio de idosos. As questões que nortearam a pesquisa foram: Que fatores influenciam nas relações familiares do idoso com ideação e tentativas suicidas? De que maneira a personalidade do idoso e suas relações familiares são indicativas da presença ou ausência de ideações e tentativas suicidas? Qual a percepção do idoso em relação ao lugar que ele ocupa na família?

O objetivo geral do trabalho foi compreender as relações familiares de idosos com ideação e tentativas suicidas. Os objetivos específicos foram identificar a história da dinâmica familiar de idosos com ideação e tentativas suicidas, desvelar o
Investigação sobre as relações familiares...

lugar que o idoso ocupa na dinâmica familiar e relacionar a estrutura de personalidade do idoso com ideação e tentativas suicidas e o contexto familiar.

A escolha do tema se deveu ao significativo aumento de casos de tentativas de suicídio em idosos, indicativos de sérios problemas de saúde pública mundial, assim como pela necessidade de prevenir o suicídio de idosos no Brasil ${ }^{(3,4)}$.

$\mathrm{Na}$ literatura $^{(5),}$ são raros os estudos brasileiros acerca do fenômeno suicídio em idosos e de investigações sobre tentativas e ideações suicidas nessa faixa etária. Motivo pelo qual tornou significativo o estudo na cidade de Teresina-PI, considerada um dos dez municípios nacionais onde o fenômeno é relevante.

Considera-se, ainda, que, este estudo tenha grande relevância para o Sistema Único de Saúde - SUS, uma vez que é dada pouca ênfase ao objetivo abordado nesse trabalho, oferecendo material para estudo, formação e capacitações nas ações de gestores e dos profissionais que trabalham em emergências nas Estratégias de Saúde da Família e dos Centros de Atenção Psicossocial - CAPS. Além de poder evitar sofrimentos, tanto da pessoa que poderá fazer tentativas ou cometer suicídio, como dos familiares que poderão perder seus idosos. 


\section{Material e métodos}

Este subprojeto foi submetido ao Comitê de ética e pesquisa da Faculdade Integral Diferencial - FACID/DEVRY, para emissão de um termo de anuência, que foi liberado em 12 de maio de 2014 sob ${ }^{\circ}$ de protocolo 470/2014.

Assegurando-lhe, entre outros direitos, o sigilo e a privacidade, após um contato inicial com os participantes, os mesmos foram esclarecidos sobre os objetivos da pesquisa através do Termo de Consentimento Livre e Esclarecido TCLE, a fim de atender aos critérios legais para a realização de pesquisa científica, em consonância aos aspectos éticos para o desenvolvimento de estudos envolvendo seres humanos, assegurados pela portaria 466/12 do Conselho Nacional de Saúde.

Neste estudo, utilizou-se da abordagem qualitativa, com o marco teórico "hermenêutico-dialético", cuja utilização possibilita uma visão ao mesmo tempo compreensiva e crítica das falas. Este método busca compreender o outro em sua história e singularidade, interpretar as falas, bem como contextualizar as narrativas e biografias no cenário histórico e nas condições da vida. Esse tipo de investigação tem como fundamento a experiência vivida, que organiza a aprendizagem da pessoa no mundo; a vivência que sintetiza as reflexões sobre a experiência; o senso comum que traduz em linguagem e atitude as opiniões e os valores sobre a experiência e a vivência; e a ação social que consiste no exercício comum e ao mesmo tempo contraditório de indivíduos, grupos e instituições, para construir suas vidas, histórias e trajetórias $^{(5)}$.

Os critérios de inclusão foram idosos com 60 anos ou mais, profissionais e familiares que têm ou tiveram contato com idosos com ideação e tentativas de suicídio. Os critérios de exclusão foram idosos com dificuldades mentais de se expressar e narrar sua história e situação e profissionais dos serviços que cumprem funções que nada tinham a ver com a convivência da pessoa idosa.

\section{Resultados e Discussão}

Foram considerados para análise 3 idosos, 1 familiar e 2 profissionais, em que seus depoimentos relataram aspectos que remetessem ao objetivo da pesquisa. Para resguardar e manter o sigilo dos participantes da pesquisa, foram usados nomes fictícios, como pode ser visto na caracterização (Quadro 1) a seguir: 
Quadro 1 - Caracterização do perfil dos participantes da pesquisa.

\begin{tabular}{|c|c|c|c|c|c|c|c|}
\hline Participante & Gênero & $\begin{array}{l}\text { Faixa } \\
\text { etária }\end{array}$ & $\begin{array}{c}\text { Estado } \\
\text { Civil }\end{array}$ & Escolaridade & Religião & Ocupação & $\begin{array}{c}\text { Tentativa: meio } \\
\text { utilizado }\end{array}$ \\
\hline Benta & $\mathrm{F}$ & 60 & Solteira & $\begin{array}{c}\text { Téc. } \\
\text { Enfermagem }\end{array}$ & Evangélica & Aposentada & $\begin{array}{c}\text { Asfixia por } \\
\text { enforcamento; } \\
\text { Intoxicação } \\
\text { medicamentosa; } \\
\text { afogamento; } \\
\text { atropelamento, } \\
\text { Autonegligência } \\
\text { alimentar. }\end{array}$ \\
\hline Joana & $\mathrm{F}$ & 66 & Viúva & $\begin{array}{c}\text { Não } \\
\text { alfabetizada }\end{array}$ & Católica & Aposentada & $\begin{array}{c}\text { Queda livre (ponte); } \\
\text { Asfixia por } \\
\text { Enforcamento. }\end{array}$ \\
\hline Raimundo & M & 60 & Casado & $\begin{array}{c}\text { Ensino } \\
\text { Fundamental }\end{array}$ & Evangélico & Aposentado & $\begin{array}{c}\text { Queda livre } \\
\text { (6 } 6^{\circ} \text { andar prédio); } \\
\text { Autonegligência } \\
\text { alimentar e } \\
\text { medicamentos. }\end{array}$ \\
\hline $\begin{array}{c}\text { Família } \\
1\end{array}$ & $\mathrm{~F}$ & 48 & Casada & $\begin{array}{l}\text { Ensino Superior } \\
\text { incompleto }\end{array}$ & Evangélica & Balconista & $\begin{array}{c}\text { Esposa do Sr. } \\
\text { Raimundo que tentou } \\
\text { o suicídio } \\
\end{array}$ \\
\hline $\begin{array}{c}\text { Profissional } \\
1\end{array}$ & $\mathrm{~F}$ & & & $\begin{array}{l}\text { Ensino } \\
\text { Superior }\end{array}$ & & Psicóloga & \\
\hline $\begin{array}{c}\text { Profissional } \\
2\end{array}$ & $\mathrm{~F}$ & & & $\begin{array}{l}\text { Ensino } \\
\text { Superior }\end{array}$ & & $\begin{array}{l}\text { Assistente } \\
\text { Social }\end{array}$ & \\
\hline
\end{tabular}

A caracterização dos participantes da pesquisa é usada em pesquisa qualitativa como forma de situar o leitor acerca do público pesquisado.

A seguir (Quadro 2), tem-se a

sistematização dos dados coletados subdivididos em três etapas: dados de identificação do caso com ideação e tentativas de suicídio, estudos de caso individuais e visão dos profissionais

Quadro2 - Sistematização da análise.

\begin{tabular}{|c|l|}
\hline $\begin{array}{c}\text { Dados de identificação do caso com tentativa } \\
\text { de suicídio. }\end{array}$ & $\begin{array}{l}\text { Dados da pessoa com tentativa de suicídio, meios utilizados e circunstâncias da } \\
\text { tentativa. }\end{array}$ \\
\hline Estudos de caso individuais & $\begin{array}{l}\text { Descrição pessoal, social e familiar; Biografia da pessoa que tentou o suicídio; } \\
\text { Estado mental que antecedeu a tentativa; Avaliação das circunstâncias antes e depois } \\
\text { do ato; Impacto do risco de suicídio na família. }\end{array}$ \\
\hline Visão dos profissionais & $\begin{array}{l}\text { Identificação de sinais e causas atribuídas a tentativas e ideações entre os idosos; } \\
\text { Avaliação da gravidade do quadro e formas de encaminhá-lo; Dificuldade para se } \\
\text { detectar, avaliar e encaminhar casos com risco de suicídio; Limites e possibilidades } \\
\text { da rede de atenção à pessoa idosa na área da saúde; Prevenção de sofrimentos } \\
\text { extremos e risco de suicídio entre pessoas idosas; Sugestões para melhorar as } \\
\text { estratégias de prevenção ao suicídio e cuidado ao idoso. }\end{array}$ \\
\hline
\end{tabular}


Após a leitura do material transcrito e com base no método "hermenêutica e dialética", foram identificadas 4 categorias analíticas, a saber (quadro 3):

\section{Quadro 3 - Levantamento de categorias analíticas.}

\begin{tabular}{|c|c|}
\hline $\begin{array}{l}\text { O lugar do idoso na dinâmica } \\
\text { familiar }\end{array}$ & $\begin{array}{l}\text { Mesmo dentro de casa, muitas vezes, o idoso não tem com quem conversar, sendo imposta } \\
\text { a ele a situação de ouvinte apenas, não tendo grande importância suas opiniões e desejos. }\end{array}$ \\
\hline $\begin{array}{c}\text { Relações familiares e tentativas de } \\
\text { suicídio }\end{array}$ & $\begin{array}{l}\text { Dificuldades de relacionamento, brigas na família, isolamento, rejeição, morte de um } \\
\text { familiar são os motivos mais frequentes de desencadeamento de suicídios em idosos. }\end{array}$ \\
\hline $\begin{array}{l}\text { Relação entre suicídio, tentativas e } \\
\text { ideação. }\end{array}$ & $\begin{array}{l}\text { Embora seja problemática qualquer investigação sobre o tema da ideação, os pesquisadores } \\
\text { dizem que muitos idosos se referem a "pensamentos de morte", "desejos de morrer", } \\
\text { "cansaço de viver", "menção à falta de sentido da vida" e "tristeza com o rumo atual da } \\
\text { própria existência". }\end{array}$ \\
\hline $\begin{array}{l}\text { Relação entre transtorno mental e } \\
\text { suicídio }\end{array}$ & $\begin{array}{l}\text { As autópsias psicológicas reportam que entre } 71 \% \text { a } 95 \% \text { das pessoas idosas que cometeram } \\
\text { suicídio estavam com diagnóstico de algum transtorno mental por ocasião de sua morte. A } \\
\text { autópsia psicológica é um método retrospectivo que reconstitui o status da saúde física e } \\
\text { mental e as circunstâncias sociais das pessoas que se suicidaram. A autópsia psicológica é } \\
\text { uma abordagem retrospectiva que permite esclarecer as situações em que ocorreu a morte, a } \\
\text { partir de fatos relevantes na vida do suicida e de seu contexto socio-cultural e relacional e } \\
\text { das possíveis causas de seu ato. }\end{array}$ \\
\hline $\begin{array}{l}\text { Religiosidade e enfrentamento às } \\
\text { ideações e tentativas }\end{array}$ & $\begin{array}{l}\text { Segundo alguns pesquisadores, há quatro fatores que podem levar uma pessoa a encontrar } \\
\text { um sentido na vida: valorização do que é importante para a pessoa; escolhas pessoais; } \\
\text { responsabilidade; significação imediata. A religião satisfaz a necessidade de sentido à vida; } \\
\text { além disso, existem evidencias de que a noção de sentido é especialmente útil para lidar com } \\
\text { crises, traumas e eventos de vida muito estressante. }\end{array}$ \\
\hline
\end{tabular}

\section{Caso Benta}

Dados de identificação da idosa com

tentativa de suicídio.

A Sr ${ }^{\mathrm{a}}$ Benta, natural de Teresina-PI, sempre residiu em sua cidade natal. Solteira, 60 anos, com ensino fundamental e técnica de enfermagem, mora com a irmã, se queixa bastante do desafeto dessa irmã e do sentimento de rejeição por parte dos familiares. Não gosta da casa onde mora, sente-se maltratada pela irmã, dona da casa. Atualmente está aposentada por invalidez, exerce atividade de bordados, é usuária do Centro de Atenção a Terceira Idade. A $\mathrm{Sr}^{\mathrm{a}}$ Benta, relata ter feito diversas tentativas de suicídio utilizando vários métodos, como por exemplo, ingestão de comprimidos, medicamentos injetáveis, enforcamento, afogamento, atropelamento e greve de fome, sem, no entanto, conseguir concluir o ato, o que atribui a Deus, que não quis. Afirma não ter compartilhado esses momentos com ninguém, e que eles (família) não perceberam porque não quiseram, e, em outro momento, relatou ter 
falado apenas uma vez para um médico que iria se jogar na frente de um carro na Avenida Frei Serafim, e que seria a última vez a tentar o suicídio. Afirma, ainda, que ouvia vozes, que lhe diziam como fazer para se matar, sempre foi revoltada pelo fato dos pais não poderem lhe dar o que queria/precisava; tentou o suicídio várias vezes, principalmente após a morte da mãe e de brigas com irmãos. Quatro anos após a morte da mãe, perdeu o pai e uma irmã, todos no mesmo ano, o que intensificou sua vontade de morrer, devido ao sentimento de culpa pela morte da mãe, considerando que não se comportou bem. Avaliando o caso dessa idosa, percebem-se atitudes ambivalentes, houve premeditação e intenção de morte, ao tempo em que a idosa demonstrava sua vontade de viver, contrastando com tentativas de suicídio, que, em geral, aconteceram quando estava em casa com a família, no local de trabalho ou nas ruas, mas sempre com proximidade de fontes de ajuda, configurando em um nível moderado de gravidade, tendo em vista a letalidade do método escolhido e das condições em que aconteceram as tentativas.

\section{Caso Joana}

Dados de identificação da idosa com tentativa de suicídio.

Sr. ${ }^{\text {a Joana, }} 66$ anos de idade, natural de Alto Longá - PI, onde trabalhava na roça.
Mora em Teresina há mais de 24 anos, exerceu a profissão de doméstica, não estudou; aposentada por invalidez, viúva, tem 12 filhos "pela vontade de Deus". Sempre sofreu agressões físicas por parte da mãe, dos irmãos, do marido e até mesmo dos filhos. Casou-se porque queria acabar com o sofrimento dentro de casa, porém com o marido teve o mesmo tratamento. Sustentou o casamento até um pouco mais de um ano, em seguida, o ex-marido faleceu. Atualmente mora com o filho mais novo; ele tem envolvimento com álcool e outras drogas, não a respeita, vive boa parte do tempo trancada em seu quarto. Tentou suicídio por afogamento e enforcamento. Afirmou não haver planejado e nem comentado com alguém sobre o assunto até hoje. Realizou a primeira tentativa se jogando de cima da ponte e logo foi socorrida e acolhida por duas freiras e pela patroa que lhe acompanhou ao hospital psiquiátrico, onde ficou internada por seis meses. A idosa relatou que atualmente não tem ideações suicidas, mas se isola e chora muito. A primeira tentativa não foi premeditada, mas a segunda foi planejada, o que configura um ato de alta gravidade.

\section{Caso Raimundo}

Dados de identificação do idoso com tentativa de suicídio.

O Sr. Raimundo é um idoso de 60 anos, casado, aposentado, exercia a 
profissão de jornaleiro e, posteriormente, representante comercial, não tem filhos, é natural do Rio de Janeiro, mora em Teresina-PI há oito anos. Tentou suicídio pulando de um prédio, não planejou, porém, sempre dizia ao irmão e à esposa que iria se matar. O idoso informa que fazia uso de medicações controladas. Quando fez a tentativa de suicídio estava em casa e logo foi socorrido pela esposa, que se encontrava no local. Foi levado para o Pronto Atendimento mais próximo, ficando internado por alguns dias. Apesar de não haver premeditado, configura-se um ato com gravidade moderada, considerando que havia indícios da intenção de se matar. Atualmente, nega ideações e tentativas suicidas, embora tenha interrompido o uso da medicação e preocupar a esposa ao dizer que a vida não tem mais sentido.

\section{$\underline{\text { O olhar da esposa (Familiar 1) }}$}

A familiar 1, é casada há nove anos com o sr. Raimundo, afirma ter passado por muitos momentos difíceis ao lado do esposo. Relatou, ainda, que há alguns dias o rs. Raimundo falava o tempo todo que a vida não tem mais sentido, vivendo muito triste. Acrescentou que a primeira grande crise dele, aqui em Teresina, aconteceu devido à recusa da medicação, bem com ir às consultas ao médico. E por conta disso, sofreu uma crise na qual quase a matou, conseguiu escapar e o trancou dentro de casa.

\section{Visão dos profissionais.}

Segundo a Profissional 1, o suicídio no idoso está sempre articulado ao sofrimento, uma dor que se torna insuportável; sempre tem questões e conflitos familiares ou perda de um vínculo amoroso. A mesma valoriza o atendimento a família na perspectiva de um suporte ao idoso. A profissional relatou, ainda, que, quando necessário, recorre ao CAPS, para que o paciente possa ser acompanhado por outros profissionais necessários ao suporte do idoso. Afirma ainda encontrar dificuldades nas redes de apoio para avaliar e encaminhar casos de idoso em risco de suicídio que não fala sobre $\mathrm{o}$ assunto. Quanto à questão do sofrimento, não há como prevenir, mas que a família tem que crescer junto, tendo um apoio e suporte. Sendo de fundamental importância falar sobre, uma vez que as redes sociais evitam falar sobre o suicídio.

A Profissional 2 relatou ser muito comum o idoso falar de solidão. E que observa que muitos idosos vivem sozinhos, eles relatam estar sempre assim, que os filhos os abandonaram, ou que custam visita-los; às vezes, os filhos acham que os idosos não têm mais autonomia, e querem tutelar esse idoso. E que os mesmos relatam não ter mais atividades, sentirem-se inúteis. 
Afirma ainda que a família precisa dar suporte, sendo necessário estar devidamente sensibilizada. Acrescentou que a família precisa dar mais suporte ao sofrimento do idoso, uma vez, que os mesmos relatam sentirem-se isolados pela família.

\section{Categorias analíticas}

O lugar do idoso na dinâmica familiar.

A relação familiar é importante para o bem-estar do idoso, ela é essencial na assistência ao idoso e nas expectativas em relação ao processo. Contudo, existem aspectos que não favorecem essa relação familiar, onde, mesmo com o fato de o idoso viver com os filhos, não é garantida a presença do respeito e do prestígio, nem a ausência de maus tratos. Mesmo dentro de casa, muitas vezes, o idoso não tem com quem conversar, sendo imposta a ele a situação de ouvinte apenas, não tendo grande importância suas opiniões e desejos $^{(6)}$.

Eu me sinto inútil por que não posso andar (...) Ainda não caiu a ficha de eu ser velho (...) Não gosto! Porque não gosto de ficar parado, inclusive eu vou falar com a auxiliadora para ver se ela arranja alguma coisa para eu fazer. Eu quero voltar a ter alguma atividade, eu gosto de ler livros, eu gosto de ler qualquer coisa. (Raimundo)

\begin{abstract}
O que é muito comum eles relatarem é a solidão (...) o idoso que vive sozinho, eles relatam que estão sempre assim, que os filhos os abandonaram, ou que custam visitalos, às vezes, essa coisa dessa forma de pensar do idoso e a forma de pensar dos filhos, estão sempre em choque no que precisa ser decidido, as vezes os filhos acham que os idosos não têm mais autonomia, e querem tutelar esse idoso (Profissional 2)
\end{abstract}

O dia a dia das relações familiares estabelece uma alternativa entre autonomia e cessão, então vai se desenvolvendo um pacto entre os seus membros e, a todo instante, além da troca recíproca de afetividade, também se estabelecem conflitos em que a palavra é insuficiente e culmina na agressão ${ }^{(7)}$ :

(...) Me sinto triste, me sinto isolada, demais (...) meu filho não me dá carinho (...) ele bebe dentro de casa, ouve muito som e depois que eu fiquei doente, eu não me dou bem com zoada, ele tem dois sons dentro de casa e uma televisão e liga todos os três de uma vez, aquilo fica em mim, reclamei, mas ai depois eu deixei. Vou para casa da minha vizinha, mas ai, depois que eu adoeci, fico mais dentro de casa, trancada dentro de casa, ai quando eu vejo que ele está dormindo, eu aproveito e desligo aqueles aparelhos (Joana). 
Analisando a dinâmica familiar, verifica-se o lugar que o idoso ocupa na casa em que reside, onde, na maioria das vezes, tem que se adaptar à nova realidade de moradia, considerando que, por suas limitações e restrições, possui dificuldades de adaptação a novas situações, tendo em vista que acabam residindo em um local sozinho ou com familiares por necessidades. Onde, muitas vezes, não atende de forma satisfatória todas as expectativas e necessidades, configurandose um ambiente conflituoso.

(...) eu não gosto da minha casa, não gosto de ir para casa (...) Quando eu chego lá, sinto vontade voltar de novo. Todo dia que saio daqui vou para igreja, segunda e sexta, vou para o CAPS (...). Vou embora 04 horas, chego em casa, tomo banho e vou para igreja. Todos os fins de semana, vou para igreja, ai quando chego em casa, ai pego e saio pra casa da minha vizinha. (Benta)

Cabe salientar que, nesse sentido, os idosos entrevistados fazem referência aos desentendimentos familiares, possuindo suas particularidades dentro de cada caso estudado, prevalecendo nos mesmos o desejo de esquecer suas famílias, uma vez que, sofrem diante do abandono por seus entes queridos.

\section{$\underline{\text { Relações familiares e tentativas de }}$} suicídio.

Os entrevistados sentem falta do carinho e da atenção dos seus familiares. Para eles, a presença da família é importante para que se sintam tranquilos, queridos e amados.

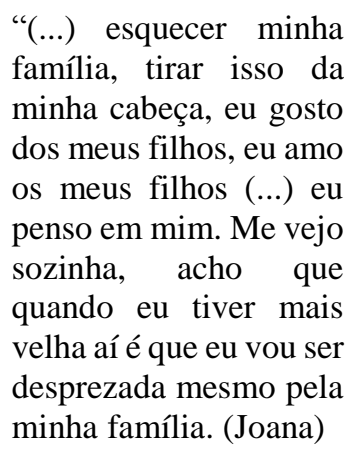

Pode-se considerar a família o meio onde as pessoas se colocam sem máscaras sociais, onde são conhecidos pelos seus defeitos e virtudes. Este apoio é, por vezes, importantíssimo para o idoso, que, se isolado da família, perde sua identidade e, consequentemente, sua lucidez.

\footnotetext{
(...) me recusei a tomar medicação e tinha muita raiva da minha família. Mamãe já tinha morrido, eu morava sozinho, meu primo, ele, por ele acho que ele disse, eu me lembro dele dizer que iria me internar numa clínica psiquiátrica, e isso me deixou aborrecido por que ele havia prometido a minha mãe que iria me amparar, amparar no sentindo de me arranjar um emprego, de cuidar mesmo. (Raimundo)
} 


\author{
A família é o meio natural de \\ inserção do ser humano. Quando há \\ ausência ou rompimento dessa inserção, o \\ idoso vive uma situação de não \\ pertencimento, sente-se ignorado, \\ desvalorizado, excluído. A família é a \\ esperança do idoso como forma de \\ manutenção das relações familiares e das \\ possibilidades de evitar o isolamento ${ }^{(8)}$.
}

(...) Eles me isolam, não querem saber de mim (...) se eles estivessem aqui, todos, eu queria abraçar todos, pedir perdão, perdão quanto mais pedir, melhor (...), não queria que eles tivessem magoa de mim (...) eles me rejeitam, eu me sinto muito rejeitada por eles (Benta)

\section{(...) Não queria tomar} as medicações o que desencadeou uma crise muito forte (...) minha família até se afastou daqui em respeito a ele, não é por despreza-lo, é porque ele não gosta da minha família (Familiar 1)

Para Minayo e Cavalcante (9), a perda de familiares ou do afeto gera maiores níveis de isolamento e solidão:

(...) minha irmã não gosta quando eu estou lá, aí fico dentro do quarto (...). Eles não gostam de mim, eu faço tudo para agradá-los, mas não sei por que eles não gostam de mim, não querem saber de mim. Tenho conflitos com minha irmã, com todos

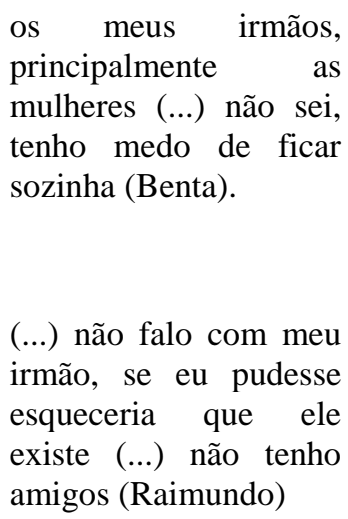

Nesse sentido, observa-se nos relatos dos participantes do estudo que os conflitos familiares acarretam em isolamento do seio familiar e social, favorecendo as tentativas e ideações suicidas, tendo como base o sentimento de abandono, solidão, angústia e vazio que os idosos sentem, potencializando essa situação na medida em que se consideram com menos valia para seus familiares.

(...) minha irmã, que
mora comigo, ficou
chateada comigo, ficou
foi tempo sem falar
comigo, zangada
comigo, essa é a que
desmaiou, que caiu no
chão porque não ia
resistir, se eu morresse,
mas porque não morri,
ficou foi tempo zangada
comigo (Benta)

\section{$\underline{\text { Relação entre suicídio, tentativas e }}$} ideação.

De acordo com as entrevistas, foi possível observar, diante das falas dos depoentes à pesquisa, fatores preponderantes para a opção de tentativa de autoextermínio. Consequências facilmente 
identificadas na vida dos idosos:

"Eu não fazia nada
sozinha, as vozes me
diziam o que era para eu
fazer, tudinho. Eu
queria morrer o tempo
todo, tentei de tudo para
morrer. Tirada por mim.
Só queria se fosse tirada
por mim"(Benta).

(...) eu já tentei me matar duas vezes numa época das crises pesada (...) quando eu cheguei cá na ponte, eu parei um pouquinho na ponte $\mathrm{e}$ fiquei chorando, me deu aquela vontade de chorar (...) eu podia era cair dessa ponte, acabar logo, tudo de uma vez, me matar já, já (...) aí eu fiquei assim, porque para mim, se eu caísse dentro daquela agua, acabava tudo isso para mim, como se acabava mesmo! (...) eu planejei colocar uma corda quando todo mundo saísse, lá dentro do meu quarto, e me pendurar (Joana).

"Eu me joguei do $6^{\circ}$ andar (...) Ela não sabe que eu sei, mas ela esconde as facas...não sei, acho que ela pensa que eu vou fazer alguma besteira" (Raimundo).

O “comportamento suicida fatal” é o resultado de um ato deliberadamente empreendido e executado com pleno conhecimento ou previsão de seu desenlace, ou seja, na sua intenção de dar fim a própria vida. A ideação suicida se refere aos vários graus de intensidade do pensamento de se matar. Alguns psicanalistas acrescentam uma nova categoria, suicídio inconsciente, para designar casos de indivíduos que se colocam em situações de risco fatal, enfrentando certos estilos de vida autodestrutivos ou mesmo provocando doenças em si mesmos. A tentativa de suicídio ou comportamento suicida não fatal, por sua vez, nomeia os atos cometidos por indivíduos que pretendem se matar, mas cujo desfecho não resulta em óbito ${ }^{(4)}$

(...) Agora, o primeiro,
foi em virtude da
medicação que não
queria tomar, não
queria ir ao médico e na
segunda ele não me
matou porque eu corri,
eu conseguir abrir a
porta e sai, era 15 horas,
muito violento
(Familiar 1)

Ainda segundo Minayo e Cavalcante $^{(9)}$, o suicídio sempre será um acontecimento complexo e de causas diversas. Nesse sentido, diversos pesquisadores mostram que transtornos afetivos e especialmente depressão sejam sintomas associados. No caso dos idosos, integra o processo de adoecimento mental a problemas de saúde física, ao isolamento, falta de suporte social e abandono familiar.

$\underline{\text { Relação entre transtorno mental e suicídio. }}$

A partir dos conteúdos retirados das entrevistas, verificou-se que os idosos participantes do estudo apresentavam transtornos mentais associados ao suicídio. 


\begin{abstract}
"Não, eu não sinto mais, antes eu vivia num choro, triste, com essa minha irmã, desse jeito, não sinto vontade de voltar pra casa, chega a hora de ir embora é triste, eu vou embora triste, mas de vez em quando me sinto muito triste" (Benta).
\end{abstract}

Grande parte dos idosos não comunicam o que sentem em relação a depressão, mas reclama de dores, tem perda de peso significativa; diminuição de apetite; culpa inadequada ou sentimentos de inutilidade; diminuição na capacidade de pensar, concentrar-se ou tomar decisões; desesperanças; pensamentos recorrentes de morte $^{(10)}$.

"Eu tive uma depressão muito forte e, segundo a minha esposa, eu me joguei do $6^{\circ}$ andar(...) Eu não lembro e nem gosto de me lembrar, porque eu fico triste... fiquei com medo, ai foi onde tudo aconteceu, no dia seguinte eu acordei com uma depressão tremenda, dizendo que ia me suicidar, ai fiz bagaceira, comecei a quebrar as coisas dentro do quarto, ai me levaram ao hospital, clinica, sei lá, cheguei, na época, a ficar internado, fiquei amarrado em uma cama, assim nos braços, me deram injeção assim e dormir (Raimundo)

(...) Eu estava tão com o pensamento ruim, eu estava tão dormente (...) eu tomo Gardenal, eu tomo remédio da

\begin{abstract}
pressão, pra labirintite, eu tomo AS, eu tenho problema da gastrite, eu fui operada da vesícula (...) me sinto deprimida, humilhada, triste da falta de respeito, de visita dos meus filhos, dos parentes, dói (Joana)
\end{abstract}

Percebe-se, que o suicídio é um fenômeno multifatorial e bastante complexo, no entanto, observou-se que a depressão foi um fator comum a todos os idosos entrevistados. Nesse sentido, podese afirmar que a depressão é um dos fatores desencadeadores do sofrimento psíquico, juntamente com os sentimentos de tristeza, vazio, solidão e de menos valia do idoso.

$$
\begin{aligned}
& \text { (...) eu nem sabia o que } \\
& \text { era depressiva, a } \\
& \text { psicóloga que me disse, } \\
& \text { que tudo o que eu } \\
& \text { sentia, era por que eu } \\
& \text { tinha perdido a minha } \\
& \text { mãe, era depressão } \\
& \text { (Benta) }
\end{aligned}
$$

Diante do evidenciado, percebe-se que há uma importante relevância em entender o idoso em sua totalidade, levando em questão o contexto em que está inserido, buscando entendê-lo enquanto pessoa dona de seu ser, de sua subjetividade, respeitando-o em seu tempo e lugar em que ocupa na família.

$\underline{\text { Religiosidade e enfrentamento às ideações }}$ e tentativas. 
O cenário religioso contemporâneo tem sido marcado por mudanças religiosas, as pessoas procuram na igreja, na fé, nas crenças, um suporte para o sofrimento vivenciado ${ }^{(11)}$.

(...) às vezes eu penso, que foi a constância de participar da família da minha ex-companheira, de bebidas, de não falar nem em Deus, eu era desviado, não falava em Deus. Ai toda vez que eu tinha surto, eu dizia que ia me suicidar, eu blasfemava, era uma blasfêmia (Raimundo)

(...) Ganhei minha vida assim ó! Ganhei minha vida com muita luta, olha o sofrimento que passei para ter a vida que eu tenho aqui, por que se eu tivesse morrido eu ia pra o inferno e eu quero ir para o céu (...) me esforço sim, me esforço, nas horas assim de choro, eu tomo esse remédio aqui, Deus está tentando salvar minha vida (Benta)

De acordo com Alexandrina ${ }^{(12),}$ o apego dos idosos à religião como um suporte e conforto, foi associado a uma menor incidência de pensamentos suicidas, mesmo após o ajuste para diversas variáveis sociais e clínicas. Além de propiciar um efeito protetor contra suicídio que a religião possui, por meio de crenças na vida após a morte e em um Deus amoroso, proporciona objetivos à vida e melhora a autoestima, fornece modelos de enfrentamento de crises, além de dar significado às dificuldades da vida, desaprovação enfática do suicídio.

O autor citado acima diz, ainda, que um modo pelo qual a religião pode proteger contra o suicídio, é a chamada dissonância cognitiva, ou seja, o quanto as crenças religiosas são incompatíveis com ideias suicidas, gerando uma menor admissibilidade do comportamento suicida.

(...) eu estou
caçando na
minha cabeça e
não acho. Quem
me dá carinho é
só Deus, meus
fillhos não me dá
carinho (...) eu
tenho vocês aqui
e todo esse
grupo aqui,
como uma
família, o povo
da igreja eu
tenho como uma
família, eu tenho
amor mais do
povo de fora,
Dra Graças a
Deus (Joana).

Percebe-se, diante dos relatos, que os idosos procuram formas de lidar com suas questões subjetivas, emocionais e limitações na religião, como forma de dar sentido à vida, cada um à sua maneira.

Não há um fator único, responsável pela tentativa ou pelo suicídio propriamente dito, uma vez que os fatores influenciadores deste fenômeno ocorrem em conjunto ${ }^{(9,13)}$. 
Entre os fatores de risco extensamente estudados na literatura internacional, se destacam tentativas prévias de suicídio, fatores genéticos, suporte social e familiar e psicopatologia. Assim, o suicídio é um problema de saúde pública que vem despertando o interesse do setor da gestão em saúde ao reconhecer os mecanismos contribuintes para este agravo, que é responsável por $1,4 \%$ do ônus global ocasionado por doenças no ano 2002 e possui estimativas de $2,4 \%$ em $2020^{(13,14,15)}$.

\section{Conclusão}

A realização dessa pesquisa permitiu compreender as relações familiares desses idosos pesquisados, com ideação e tentativas suicidas, frente às dificuldades e limitações vivenciadas pelos mesmos em seu meio familiar.

As tentativas de suicídio vêm se apresentando como um problema de saúde pública mundial, um desafio para os profissionais de saúde. Assim, é fundamental conhecer as variáveis implicadas em tal fenômeno sob a ótica do próprio idoso, na tentativa de prevenir o sofrimento psíquico acompanhado, por vezes, de ideações e tentativas de autoextermínio.

Verificou-se que os idosos deste estudo que vivenciam conflitos nas relações familiares, se sentem desprezados, abandonados e rejeitados pelos familiares, motivos pelos quais se culpam; convivem em meio familiar, mas de modo isolado, vivem isolados socialmente e em sofrimento psíquico, com transtornos mentais, que favorecem a ideação suicida. De tal modo que os mesmos buscam a religiosidade como formas de enfrentamento e de dar sentido à vida.

Neste sentido, acredita-se que o suicídio constitui uma espécie de escape ao intenso sofrimento, quando associado a necessidades frustradas, baixa autoestima, afetividade negativa insuportável, estreitamento de opções associadas a sentimentos de desesperança, desamparo, rejeição e desejo de fuga por parte do sujeito. 
Revista Eletrônica Gestão \& Saúde ISSN: 1982-4785 Albquerque PRR, Cavalcante ACS, Oliveira CAB et al

\section{Referências}

1. Organização Mundial de Saúde. Transtornos Mentais e Comportamentais. Departamento de Saúde Mental. Prevenção do suicídio: Um Manual para profissional da saúde em Atenção Primária. Genebra; 2000.

2. World Health Organization. World report on violence and health. Geneva; 2002.

3. Minayo MCS, Figueiredo AEB, Mangas RM. Estudo sobre tentativas de suicídio em idosos sob a perspectiva da saúde pública (Projeto de Pesquisa). Rio de Janeiro (RJ): Fiocruz; 2013

4. Minayo MCS, Cavalcante FG, Mangas RM, Souza JRA. Motivos associados ao suicídio de pessoas idosas em autópsias psicológicas. Trivium. 2011 1: 109-117.

5. Minayo MCS, Figueiredo AEB, Silva RM. (Organizadoras). Comportamento Suicida de Idosos. Fortaleza: Edições UFC, 2016. 437p.

6. Françoso FG. A Ressocialização do Idoso a partir da Comunicação através da Atividade Física. São Paulo: Conferência Brasileira de Comunicação e Sáude. Acesso em: 03 de Outubro de 2013. Disponível em: http://www.projetoradix.com.br/arq_artigo/X 08.pd $\underline{\mathrm{f}}$

7. Rocha SMC. O idoso e os contextos familiares da contemporaneidade brasileira: aspectos sócio jurídicos. In: XXI Encontro Nacional do CONPEDI; 2012; Uberlândia. Florianópolis: Fundação Boiteux; 2012. 2328-2358

8. Herédia VB, Cortelletti IS, Casara MB. Abandono na velhice. Rio de Janeiro. Acesso em 22 de novembro de 2013. Disponível em: http://www.unati.uerj.br/tse/scielo.php?script=sci_a rttext\&pid=S151759282005000300002\&Ing=pt\&nr $\mathrm{m}=$ iso.
Investigação sobre as relações familiares...

9. Minayo MCS, Cavalcante FG. Tentativas de suicídio entre pessoas idosas: revisão da literatura. Ciênc. Saúde Coletiva. 2015; 20: 1751-1762

10. Papalia M, Olds SW. Desenvolvimento Humano. $7^{\circ}$ ed. Porto Alegre: Artmed; 2000

11. Robbins J. Sobre alteridade e o sagrado em uma época de globalização: o "trans" em "transnacional" é o mesmo "trans" de "transcendente"? Mana. 2008; 14 (1): 119-139

12. Meleiro AMAS, Teng CT, Wang YP. Suicídio: Estudos Fundamentais. Segmento Farma. 2004; 1: 13-36.

13. World Health Organization. Preventing suicide: a resource for general physicians. Department of Mental Health, Geneva: World Health Organization; 2000.

14. Brasil. Ministério da Saúde. Estratégia Nacional de Prevenção do Suicídio. Prevenção do Suicídio: Manual dirigido a profissionais das equipes de saúde mental. Brasília (DF): Ministério da Saúde; 2006.

15. Oliveria EN, Félix TA, Mendonça CBL et. Al. Tentativa de suicídio por intoxicação exógena: contexto de notificações compulsórias. Revista Eletrônica Gestão \& Saúde. Vol.06, Nº. 03, Ano 2015 p. 2497-11.

\section{Participação dos autores:}

ALBQUERQUE, PRR trabalhou na concepção teórica, coleta de dados, análise qualitativa, elaboração e redação final do texto.

CAVALCANTE, ACS trabalhou na concepção teórica, coleta de dados, análise qualitativa, elaboração e redação final do texto.

OLIVEIRA, CAB trabalhou na análise qualitativa, elaboração e redação final do texto

MOREIRA, PC trabalhou na análise qualitativa, elaboração e redação final do texto.

SILVA, IM trabalhou na análise qualitativa, elaboração e redação final do texto.

GONDINHO, BVC trabalhou na análise qualitativa, elaboração e redação final do texto. 
Revista Eletrônica Gestão \& Saúde ISSN: 1982-4785

Albquerque PRR, Cavalcante ACS, Oliveira CAB et al

Recebido: 28.03.2017

Revisado: 20.04.2017

Aprovado: 23.07.2018
Investigação sobre as relações familiares... 